\title{
Near-Death Experiences and Self-Transformation
}

\author{
John Pennachio, Ph.D. \\ Adirondack Community College
}

\begin{abstract}
The near-death experience (NDE) may be one of many mechanisms that may activate renewal and transformation, fundamental tendencies of the psyche. An examination of three successive NDEs in one individual suggests that such alterations of consciousness weaken ego control and foster transcendence of the ego, promoting transformation and regeneration.
\end{abstract}

\section{Transformation and Renewal}

Altered states of consciousness have the potential to release the ego and allow the psyche to move beyond the boundaries of the skin, beyond the confines of the material world, beyond the limitations of time and space. These attributes designate ego transcendence and may also characterize psychotic, psychedelic and mystical experiences. As I have argued elsewhere (Pennachio, 1986), near-death experiences have many of the qualities of mystical experiences. Further, like psychotic and psychedelic experiences, near-death experiences (NDEs) may also be a vehicle for regeneration and transformation.

Western psychiatry avoids and for the most part seems to fear exploration of internal mental states. Almost anything that advances a change in consciousness is systematically discouraged. The see-touch "objective" world of the senses is defined as the only reality and any movement away from its perception is regarded as disordered, disabling and hallucinatory. Traditional science has exemplified these

Dr. Pennachio is Associate Professor of Psychology at Adirondack Community College. Requests for reprints should be addressed to Dr. Pennachio at Adirondack Community College, Glens Falls, NY 12801. 
beliefs in divising an elaborate methodology to validate the external world and negate and invalidate any internal data.

However, there is an alternative to the traditional and orthodox conceptions of psychosis and psychedelic experience. Rather than identifying such experiences as degenerative, some have sought to depict psychotic and psychedelic experiences as potentially constructive and regenerative. A primary aspect of this position is that such experiences promote new psychological unity and greater awareness. Symptoms, rather than being alien aspects of a disease, are essential steps on the road toward renewal and self-transformation.

These alternative views are evident in the work of Ronald Laing (1967) and John Weir Perry (1976), among others. The psyche, during psychotic experience, can regenerate itself, and the resulting reorganization can lead to greater internal harmony and increased selfawareness. This self-awareness often leads to feelings of unification with nature or an awareness of the "all" or cosmic awareness (Pennachio, 1983). Symptoms, such as weak ego boundaries, for example, point the way for regeneration and are to be encouraged rather than suppressed or prohibited. As Laing (1967) contended, symptoms are to be viewed as part of an orderly and natural sequence of events.

Both Laing and Perry regard psychosis as a journey through inner space and facilitate identification with symptoms, since symptoms promote this journey and are not part of a disease process. According to Kenneth Pelletier and Charles Garfield (1976), the transpersonal nature of the experience must be recognized in order to reap the benefits of this journey. "Whether such an experience degenerates into chronic psychosis or is integrated following a regenerative psychosis is dependent on the recognition of the transpersonal themes that lend a degree of coherence to the chaotic behavior of a diagnosed psychotic" (Pelletier \& Garfield, 1976, pp. 91-92).

The same view has been taken by Stanislav Grof (1980) in his work with psychedelics and transformation. Grof maintains that the psychedelic experience can be an essential and necessary part of self-transformation. LSD may act as a catalyst for a mystical experience, offering great promise for renewal and regeneration. Grof's research equates the psychedelic experience with the mystical experience. Mystical experience is regarded as an inherent tendency of the psyche, not a function of psychedelic drugs. The psychedelic mystical experience can allow the psyche to transcend many socially imposed limitations and internal conflicts.

An altered state of consciousness carries the potential for transformation because it erodes culturally induced ego control, thereby elim- 
inating the restrictions imposed on ego and the psyche. If transformation is an inherent aspect of the psyche, it is most likely to occur when social consciousness is suspended. Any experience that weakens the social hold on the ego increases the possibility that this transpersonal and transformative tendency will appear. These assumptions underlie the work of Laing, Perry and Grof.

Ego transcendence frequently accompanies catharsis and regeneration. Catharsis and regeneration are powerful instruments for transformation and are often referred to as a death/rebirth experience. An overview of this process is taken from the work of Grof:

After the subject has experienced the limits of total annihilation and "hit the cosmic bottom," he or she is struck by visions of blinding white or golden light... The general atmosphere is one of liberation, salvation, redemption, love and forgiveness. The subject feels unburdened, cleansed, and purged, and talks about having disposed of an incredible amount of personal "garbage," guilt, aggression and anxiety. This is typically associated with brotherly feelings for all fellow men and appreciation of warm human relationships, friendship and love. Irrational and exaggerated ambitions, as well as cravings for money, status, fame, prestige, and power, appear in this state as childish, irrelevant and absurd. There is often a strong tendency to share and engage in service and charitable activities. The universe is perceived as indescribably beautiful and radiant. All sensory pathways seem to be wide open and the sensitivity to and appreciation of external stimuli is greatly enhanced. The individual tuned into this experiential area usually discovers within himself or herself genuinely positive values, such as a sense of justice, appreciation of beauty, feelings of love, and self-respect as well as respect for others. These values, as well as the motivations to pursue them and live in accordance with them, appear on this level to be intrinsic to human nature. They cannot be satisfactorily explained in terms of compensation, reaction-formation, or sublimation of primitive instinctual drives. The individual experiences them as genuine and integral parts of the universal order. (Grof, 1980, p. 85)

Following are three successive near-death experiences that indicate renewal and transformation. The experiences demonstrate that some of the transformative properties that may accompany psychotic and psychedelic experiences may also be associated with near-death experiences.

\section{NDEs and Transformation}

This is an account of one person's separate and progressive neardeath experiences. A woman, whom I will call Heidi, identified herself 
to me following a presentation I made on the mystical aspects of neardeath experiences. These experiences, through their sequence, reveal catharsis and transformation. They provide some very interesting insights into what may be one of the most essential aspects of altered states of consciousness and NDEs-renewal and regeneration, or death, rebirth and transformation.

While Heidi was pregnant in late 1969 a deliberate drug overdose produced three consecutive near-death experiences within four weeks. This suicide attempt, confirmed by family and hospital records, resulted in a Caesarean section and brought on subsequent unconsciousness and cardiac arrest. The three accounts depicted here illustrate many attributes of NDEs identified in the literature. What is informative about this case is the manner in which these experiences occurred and what can be learned from them.

While there have been many positive life changes since these encounters, Heidi has been reluctant to share these experiences with others. This is the first time, in fact, that anyone has been told about these NDEs in their entirety. A verbatim account of these experiences follows, with each encounter being described as a trip.

\section{First Trip}

There is no fear in dying. It is very relaxing and it's like being born. Everything is easy and gentle. [Upon going into a coma, Heidi said, she felt as though she had gone to hell.] Someone told me that I didn't belong there, to turn around. When I did, I turned into darkness. I half ran and half walked; it seemed like hours, but it must have been only seconds. I don't know how long. Then there was Christ and he told me it was not my time. There was confusion and I didn't know where to go. I had the feeling that I was not wanted in the afterlife and was not wanted on earth. I wondered where I was going. Then there was nothing, absolutely nothing!

My entire life appeared before me. I went through my whole life and relived everything. Every stage of my life was there, with everything that I had done. Then there was a feeling of falling that I did not fight and just allowed to happen. I then found myself alone, completely alone-totally lost with no fear of anything. There was a calm. It felt like my life was being turned around, I don't know, just seemed like I was being turned around.

Then there was a feeling of not wanting to return. I was lost but it seemed like maybe there was another road to take-but lost. Everything was calm, no fear at all. 


\section{Second Trip}

Shortly after the first episode another cardiac arrest produced a second NDE. This encounter was unpleasant and unlike the first.

It was frightening, devastating. The faces of people were distorted. Some were laughing and others were screaming at me. It was as if I were sorting out reality; sorting out what true people are. One face looked like my closest friend, but ugly and hateful. I wanted to run but could not. I felt that I should stay and sort things out. I kept saying to myself: "Why is this happening?" "What is this?"

There was a feeling of great loss and much loneliness. It was more devastating than you can ever imagine. I was at the point where I just could not tell the difference between heaven and hell and didn't think there was a heaven.

[When she gained some of her strength and was still "half in and half out," a clergyman appeared at the foot of her bed. Not strong enough to engage him in dialogue, she did, however, want to talk with him.] I wanted to tell him of my disappointment with religion for all the lies. I was convinced there was no eternal peace.

I was able to evaluate all of my friends. They appeared to me as they actually were. I knew who was and was not my friend.

\section{Third Trip}

While Heidi was in the hospital she experienced yet another NDE. This third experience was different than the two that preceded it. Heidi said it was difficult to convey an overall impression of this encounter and described it as a kind of energy or power that brought about a change in her whole body.

I was out of my body and being filled with knowledge. This knowledge led to great love and understanding of humanity. There was a sense of cramming, as if I was being crammed with knowledge and power. It was like taking a flat tire and pumping it full of air.

This was like a training period for some special thing. Only you are aware of what the training is for. No one else is aware. You are training for the transformation which follows. I was being turned completely around; I was being made over. I was made different; I'm not the person I was.

\section{Changes Following The NDES}

Following the third experience there were a number of changes in Heidi's life. She viewed herself as more capable and better able to cope 
with life. She said she felt greater control over her mind and body and increased self-confidence.

Her compassion for others was, and remains, greater than it has ever been. There was a feeling of tremendous love for humanity. During the third experience she made a promise to care for children. This has been realized as her home has been opened to nearly 100 homeless and unwanted children during the past 17 years.

Artificial and imposed social distinctions, like prejudices and biases, fell away, she said. There was an ability to see more clearly, with the realization that social reality is a constructed fiction. Further, there was disrespect for institutional religion, even though Heidi was reared in a religious family.

The experience gave Heidi a greater sense of others and an awareness of people in a new way. Insights gained from intuitions offer both guidance and fascination, she said. Life has provided many confirmations of these intuitions and impressions. Additionally, she now experiences out-of-body states as a matter of choice and can decide where to travel. Her out-of-body episodes are characterized as enjoyable and restorative.

\section{Conclusion}

The description of these near-death experiences creates the impression of psychological movement and growth. They permitted an examination of past and present life in ways that deviated from ordinary modes of perception and consciousness. All three encounters gave the experiencer the feeling of "being turned around," an interesting way of characterizing survival from a suicide attempt.

These accounts point to the transformation that may accompany near-death experiences. In this case, it is as though the physical traumas were necessary and catalytic for the alterations in consciousness and the psychological death and rebirth that followed. The first encounter began a process that gained completion after two additional near-death episodes. Blissful feelings and the life review were aspects of the first experience. The second symbolized purging and psychological death. Rebirth was indicated in the third encounter.

These near-death experiences lend support to those conceptions that argue there is a restorative function inherent in the psyche that facilitates catharsis and self-healing. The NDE may be one way of stimulating this activity, an activity more likely to manifest when ordinary consciousness is transcended. An altered state of consciousness is fre- 
quently equated with the loss of ego control, one primary precursor for renewal and transformation. Near-death experiences, therefore, can elicit the most crucial transformative and transpersonal experience of a person's life.

\section{References}

Grof, S. (1980). LSD Psychotherapy. Pomona, CA: Hunter.

Laing, R. D. (1967). The Politics of Experience. New York, NY: Pantheon.

Pelletier, K., \& Garfield, C. (1976). Consciousness: East and West. New York, NY: Harper \& Row.

Pennachio, J. (1983). Nature and consciousness: Separation or unification. Australian Journal of Transpersonal Psychology, 3, 207-215.

Pennachio, J. (1986). Near-death experience and mystical experience. Journal of Religion and Health, 25, 64-72.

Perry, J. W. (1976). Roots of Renewal in Myth and Madness. San Francisco, CA: JosseyBass. 